\title{
DAMPAK PENDAPATAN BADAN USAHA MILIK DESA (BUMDES) TERHADAP KEMISKINAN MASYARAKAT (Studi Kasus Desa Peunaga Pasi Kecamatan Meureubo Kabupaten Aceh Barat
}

\author{
Yuliati $^{1)}$ Alisman $^{2)}$, dan Bukhari ${ }^{3)}$ \\ 1) Prodi Ekonomi Pembangun Fakultas Ekonomi Universitas Teuku Umar \\ ${ }^{2,3)}$ Dosen Prodi Ekonomi Pembangunan Universitas Teuku Umar \\ Email: atyuli0012@gmail.com alisman@utu.ac.id dan clbukharwb@utu.ac.id
}

\begin{abstract}
The role of village-owned enterprisesis an institution managed by the government and the village community which aims to strengthen the village economy. This research was conducted for see the impact of village-owned enterprises in overcoming poverty in Peunaga Pasi village, Meureubo subdistrict, West Aceh district year 2020. This study aims to determine the impact of village-owned enterprises in overcoming poverty. The analytical method used is descriptive qualitative, using a sample of 22 respondents.the results of this study indicate that village-owned enterprises have a positive impact on poverty. the existence of village-owned enterprises has reduced the poverty level of the community in the village of Peunaga Pasi, Meureubo sub- district, West Aceh district
\end{abstract}

Keywords: Village Owned Enterprises, community poverty, Aceh Barat Regency.

\section{Pendahuluan}

Pada peraturan pemerintah nomor 47 tahun 2015 menuturkan bahwa desa memegang kekuasaan sendiri untuk mengelola SDA dan haluan pengembangan di Desa. Berjalannya regulasi tersebut membuat banyak perubahan bagi masyarakat Desa. Desa kini memiliki otonomi sendiri untuk membangun dan menembus era indenpendensi sendiri sebagaimana daerah daerah indenpendensi tahap Kabupaten dan provinsi. Desa memegang otonomi dan kekuasaan pada program sosial masyarakat,dan finansial oleh karena itu desa sudah tidak lagi menunggu perintah dari Kecamatan, Kabupaten, Provinsi, atau pun pusat.

Di masa kemandirian Daerah dan Desa, Desa menggambarkan pusat pertumbuhan masyarakat selaku manifestasi terhadap itensitas beragam aspek, sebab arah berkembangnya kemandirian yaitu meratakan kemakmuran masyarakat, juga tergolong masyarakat desa. Saat ini Desa menempuh masa yang aktual dalam peraturan Desa.
Undang-Undang Nomor 6 tahun 2014 tentang Desa, mempunyai misi mendampingi Desa selaku kunci kehidupanmasyarakat Indonesia yang diinginkan oleh Undang-Undang Dasar 1945. Desa diminta bisa berperan mandiri menurut ekonomi,sosial,budaya bahkan politik.

Selanjutnya aktivitas desa juga tergantung atas kerja sama masyarakat dalam memajukan pembangunan Desa, sanggup meningkatkan dan melebarkan nilai kemasyarakatan, adat, ekonomi, dan keahlian. Hadirnya Undang-undang Desa dengan standar Anggaran Dana Desa (ADD), baik bagi infrasruktur ataupun pemberdayaan masyarkat, sudah terlihat secara langsung untuk mensejahterakan masyarakat. Konsep tersebut juga bisa terlaksana di Kabupeten Aceh Barat yang terdiri dari 322 Desa, yang terpecah dalam 12 kecamatan dan pada umumnya telah mempunyai Badan Usaha Milik Desa (BUMDes) juga terbilang Meureubo Kabupaten Aceh Barat. Dari segi pengelolaannya BUMDes di Kecamatan Meureubo tidak aktif sepenuhnya. 
Asas hukum terentuknya BUMDes yakni Undang-Undang No 6 Tahun 2014 tentang desa, serta PP 11 tahun 2021 tentang BUMDES yakni badan hukum yang dibangun oleh desa yang bertujuan untuk menata usaha, memungsikan aset, menumbuhkan investasi dan produktivitas, mempersiapkan jasa pelayanan, dan/atau mempersiapkan beragam usaha lainnya untuk kesejahteraan masyarakat Desa. Badan Usaha Milik Desa terdiri atas BUM Desa dan BUM Desa bersama. PP 11 tahun 2021 tentang BUMDes menuturkan bahwa tujuan dari Badan Usaha Milik yaitu untuk:

1. Melaksanakan aktivitas usaha ekonomi dengan manajemen usaha, dan menumbuhkan investasi dan produktivitas ekonomi, dan kapasitas Desa;

2. melaksanakan pelayanan umum dengan mempersiapkan barang atau jasa dan pemuasan kepentingan umum masyarakat Desa, dan memanajemen lumbung pangan Desa;

3. mecapai keuntungan atau laba bersih pada eskalasi pendapatan asli Desa juga menumbuhkan sebanyak mungkin manfaat akan sumber daya ekonomi masyarakat Desa;

4. Penggunaan Aset Desa guna melahirkan nilai tambah pada aktiva Desa;

5. Menumbuhkan ecosystem ekonomi digital di Desa;

Kebijakan Pemerintah Nomor 11 tahun 2021 mengenai Badan Usaha Milik Desa diabadikan Presiden Joko Widodo pada tanggal 2 Februari 2021 di Jakarta. Kebijakan Pemerintah Nomor 11 tahun 2021 mengenai Badan Usaha Milik Desa diundangkan Menkumham Yasonna H Laoly di Jakarta pada tanggal 2 Februari 2021. (PP RI no 11 tahun 2021).

Pendirian BUMDes menggambarkan wujud dari manajemen ekonomi kreatif desa yang dijalankan secara suportif, partisifatip, emansifatif, transparasi, akuntabel, sustainable. Oleh sebab itu diperlukan cara yang benar untuk menjadikan BUMDes agar bisa aktif dan independen. Agar memperoleh destinasi dari BUMDes yaitu dengan melengkapi kebutuhan yang bermanfaaat bagi masyarakat dengan pelayanan distribusi barang dan jasa yang diatur masyarakat dan pemerintah desa.
Kabupaten Aceh Barat terdiri dari 12 kecamatan dan 322 gampong dengan kode pos 23615-23682 (dari total 289 kecamatan dan 6.497 gampong di seluruh Aceh). Pada tahun 2010, jumlah penduduk di wilayah ini adalah 172.896 jiwa (dari penduduk seluruh Aceh yang berjumlah 4.486 .570 jiwa) yang terdiri atas 87.682 pria dan 85.214 wanita (seks rasio 102,90). Dengan luas daerah 275.872 ha (dibanding luas seluruh provinsi Aceh 5.677.081 ha).

Peunaga Pasi yaitu salah satu area yang terletak di tepi pantai sehinga sangat cocok dijadikan sebagai lokasi wisata.Tempat luas dan nyaman dan juga tersedia banyak kantin dan area bermain yang luas. Wisata air waterboom peunaga pasi mulai beroperasi dari tahun 2018. Selain waterboom juga terdapat beberapa asset lainnya yang merupakan bagian dari BUMDes.Berikut beberapa asset aktif BUMDES yaitu Tratak,Kursi,Hand Traktor,Sound System,Becak,apaerontok Padi, Pompa air minum isi ulang,Wahana Tempat Bermain anak serta 8 ( delapan ) warung permanen di tempat wahana bermain anak.

Berikut pendapatan BUMDes selama 3 tahun terakhir:

\begin{tabular}{l|lll|}
\hline TAHUN/BULAN & 2018 & 2019 & 2020 \\
\hline IANUARI & 1.130 .000 & 4.630 .000 & 8.225 .000 \\
\hline FABRUARI & 3.800 .000 & 6.020 .000 & 5.780 .000 \\
\hline MARET & 6.060 .000 & 8.238 .000 & 3.449 .000 \\
\hline APRIL & 3.835 .000 & 10.685 .000 & 810.000 \\
\hline MEI & 1.400 .000 & 2.000 .000 & 895.000 \\
\hline JUNI & 550.000 & 7.382 .000 & 2.470 .000 \\
\hline JULI & 3.250 .000 & 9.027 .000 & 2.900 .000 \\
\hline AGUSTUS & 6.945 .000 & 5.204 .000 & 8.376 .000 \\
\hline SEPTEMBER & 2.990 .000 & 5.876 .000 & 2.075 .000 \\
\hline OKTOBER & 4.490 .000 & 5.756 .000 & 3.000 .000 \\
\hline NOVEMBER & 3.000 .000 & 1.552 .000 & 5.782 .000 \\
\hline DESEMBER & 260.000 & 12.121 .000 & 6.247 .000 \\
\hline TOTAL & 37.710 .000 & 78.491 .000 & 50.009 .000 \\
\hline
\end{tabular}

Pada tabel di atas terlihat bahwasanya capaian pendapatan Badan Usaha Milik Desa(BUMDes) di Peunagaga Pasi sudah semakin meningkat. Capaian tersebut terbukti dengan meningkatnya pendapatan pertahun. capaian tersebut tersebut terbukti dengan meningkatnya pendapatan dari tahun ke tahun dan semakin majunya Badan Usaha Milik Desa(BUMDes) dengan bertambahnya jumlah asset dan berkembangnya beberapa usaha sehingga berdampak pada pendapatan BUMDes yang semakin meningkat dan juga berdampak bagi kesejahteraan masyarakat Peunaga Pasi.

BUMDes di Aceh Barat pertama kali berdiri pada tahun 2012 dengan diadakan 
program dana bergulir yang salurkan serentak ke seluruh desa di Kabupaten Aceh Barat, namun tidak semua desa memanfaatkan dengan baik ada banyak desa yang BUMDesnya tidak berjalan bahkan lumpuh total akibat penyalahgunaan dana dan juga disebabkan oleh karakter masyarakat yang berbeda dan menganggap dana tersebut sebagai dana hibah dan juga karena pengurus yang kurang aktif atau kurang cermat dalam menjalankan BUMDes maka dari hal tersebut dapat disimpulkan bahwa BUMDes di Aceh Barat secara umum tidak aktif.

\section{Literatur Review \\ Badan Usaha Milik Desa (BUMDes)}

Asas hukum terentuknya BUMDes yakni Undang-Undang No 6 Tahun 2014 tentang desa, serta PP 11 tahun 2021 tentang BUMDES yakni badan hukum yang dibangun oleh desa yang bertujuan untuk menata usaha, memungsikan aset, menumbuhkan investasi dan produktivitas, mempersiapkan jasa pelayanan, dan/atau mempersiapkan beragam usaha lainnya untuk kesejahteraan masyarakat Desa.

$$
\text { Jadi BUMDes adalah suatu }
$$
usaha/lembaga yang berfungsi untuk mengembangkan ekonomi desa dengan usaha yang dikembangkan untuk mendapat keuntungan dan laba. BUMDes yaitu suatu institusi yang diakui menajadi badan usaha yang bisamendukung pemerintah dan masyarakat dan menumbuhkan juga melengkapi keperluan harian, sebagai probabilitas usaha, memperluas pengetahuan masyarakat desa baik dengan cara menumbuhkan kapasitas desa ataupun memungsikan SDA. BUMDes mampu menjadi alasan estimasi untuk menyalurkan daya usaha masyarakat desa, kapasitas desa, melaksanakan dan memungsikan kapasitas SDA desa juga memaksimalkan Sumber Daya Manusia (Warga Desa). (dewi dalam Maryunani, 2014).

\section{Dampak}

Pendapatan merupakan segala perolehan baik berbentuk uang atau barang yang bersumber dari kelompok lain ataupun hasil industri yang diperhitungkan atas dasar sejumlah uang dari asset yang legal di era tersebut. Pendapatan merupakan akar penghasilan seseorang untuk mencukupi keperluan harian dan amat penting artinya bagi kesinambungan hidup (Suroto, 2000).

\section{kemiskinan}

Kemiskinan melahirkan masalah sosial yang terus menerus ada di kehidupan masyarakat pokok permasalahan dari kemiskinan itu sendiri yaitu melibatkan beragam bentuk atau kepribadian masyarakat. Atau dapat dikatakan kemiskinan melahirkan kasus kehidupan yang bersifat luas atau global, maknanya masalah kemiskinan telah menjadi perhatian dunia, dan masalah tersebut ada di setiap negara,meskipun akibat dari kemiskinan itu sendiri berbeda-beda (Nurwati 2008).

\section{Metodelogi Penelitian}

Observasi ini dilakukan terhadap Badan Usaha Milik Desa (BUMDes) Peunaga Pasi kecamatan Meureubo Kabupaten Aceh Barat. Dalam obsevasi ini penulis memakai sample sebanyak 22 responden yaitu karyawan BUMDes dan sejumlah perangkat desa beserta lembaga desa.

\section{Hasil dan Pembahasan \\ Pendapatan Badan Usaha Milik Desa (BUMDes) Peunaga Pasi}

Setelah melakukan perhitungan maka diperoleh hasil $r$ hitung $=0,682$ maka jika dihubungkan dengan $r$ tabel maka tahap kepercayaan $95 \%$ dengan $n=22$ adalah 0,423 pada tahap siginifikan $5 \%$ maka nilai rxy hitung lebih besar dari nilai $r$ tabel product moment yaitu 0,682 > 0,423 dengan 22 responden.

\section{PENDAPATAN BUMDES PEUNAGA PASI TAHUN 2018-2020}

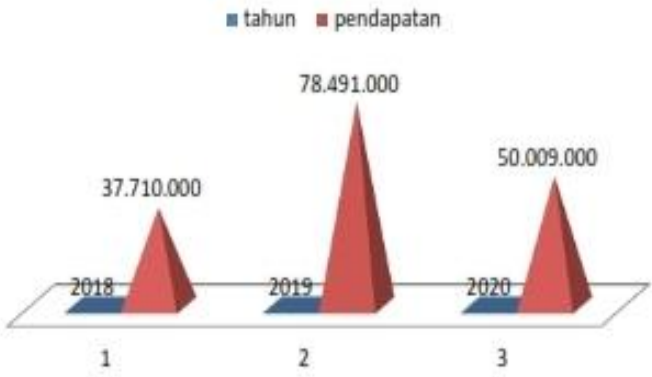

Pada grafik di atas terlihat bahwasanya capaian pendapatan Badan Usaha Milik Desa (BUMDes) di Peunagaga Pasi sudah semakin meningkat. Capaian tersebut terbukti dengan meningkatnya pendapatan pertahun. capaian tersebut tersebut terbukti dengan semakin majunya Badan Usaha Milik desa dengan bertambahnya beberapa asset dan berkembangnya beberapa usaha sehingga berdampak pada pendapatan BUMDes yang semakin meningkat dan juga berdampak bagi kesejahteraan masyarakat Peunaga Pasi. 
Setelah melakukan perhitungan maka diperoleh hasil $r$ hitung $=0,682$ maka jika dihubungkan dengan $r$ tabel maka tahap kepercayaan 95\% dengan $n=22$ adalah 0,423 pada tahap siginifikan $5 \%$ maka nilai rxy hitung lebih besar dari nilai $r$ tabel product moment yaitu 0,682 >0,423 dengan 22 responden.

\section{Uji tingkat Kolerasi}

Rumus Korelasi Product Moment digunakan untuk melihat bagaimana pengaruh yang terjadi antara variabel bebas dengan variabel terikat :

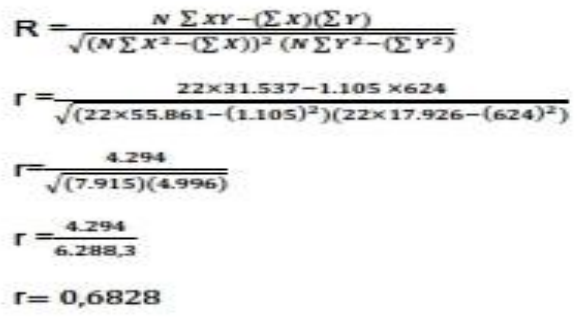

\begin{tabular}{|l|l|}
\hline \multicolumn{1}{|c|}{ Nilai } & \multicolumn{1}{c|}{ Makna } \\
\hline $0,00-0,19$ & Sangat rendah/sangat lemah \\
\hline $0,20-0,39$ & Rendah/lemah \\
\hline $0,40-0,59$ & Sedang \\
\hline $0,60-0,79$ & Tinggi/kuat \\
\hline $0,80-1,00$ & Sangat tinggi/ sangat kuat \\
\hline
\end{tabular}

Berdasarkan petunjuk diatas dapat dilihat bahwa tingkat korelasi antara variabel bebas (X) dampak BUMDes dengan variabel terikat (Y) tingkat kemiskinan berada pada tingkat interprestasi tinggi, yaitu antara 0,60-0,79.

\section{Uji Determinasi}

Tujuan dari uji determinan adalah untuk mengukur seberapa banyak persentase (\%) Variabel Bebas (X) dampak BUMDes dan Variabel Terikat (Y) tingkat kemiskinan masyarakat. Untuk rumus yang dipakai yaitu: D $=\mathrm{r}^{2} \times 100 \%$ setelah dilakukan perhitungan maka uji determinan adalah sebagai berikut :

$D=(r x y)^{2} \times 100 \%$

$\mathrm{D}=(0,68)^{2} \times 100 \%$

$D=0,4624 \times 100 \%$

$D=46,24 \%$.

Setelah melakukan perhitungan menggunakan rumus $D=r^{2} \times 100 \%$ maka diketahui hasil uji determinasinya adalah $46,24 \%$. Hal ini berarti bahwa variabel bebas $(\mathrm{X})$. Dampak Pendapatan BUMDes telah mampu menerangkan sekitar 46,24\% terhadap kemiskinan masyarakat $(\mathrm{Y})$. Sementara sisanya sekitar $53,76 \%$ dipengaruhi oleh factor-faktor lainnya.

Dampak Pendapatan BUMDes telah mampu menerangkan sekitar $46,24 \%$ terhadap kemiskinan masyarakat (Y). Sementara sisanya sekitar $53,76 \%$ dipengaruhi oleh factor-faktor lainnya. Dari hasil perhitungan tersebut dapat diketahui bahwa nilai $R$ menunjukkan besarnya korelasi sebesar 0,68. Rentang hubungan suatu variabel berkisar antara 0-1. Semakin mendekati 1, variabel tersebut memiliki hubungan yang kuat diantara keduanya. Sehingga dapat diartikan bahwa Badan Usaha Milik Desa mempunyai hubungan yang kuat terhadap kemiskinan masyarakat. Nilai $R$ square sebesar 0,682 , besar angka tersebut sama dengan $46,24 \%$. Sehingga variabel Badan Usaha Milik Desa mempengaruhi variabel kemiskinan masyarakat sebesar 46,24\%. Sementara sisanya, yaitu $53,76 \%$ dipengaruhi oleh faktor-faktor lainnya.

Sementara tingkat kemiskinan di desa Peunaga Pasi menurut data yang di dapat berdasarkan hasil koordinasi dengan PLD dan sekdes Peunaga Pasi tingkat kemiskinan selama tiga tahun terahir mengalami penurunan. Dari data yang didapat masyarakat miskin pada tahun 2018 berjumlah 39 KK,sementara pada tahun 2019 sebanyak 37 KK,dan pada tahun 2020 berjumlah 36 KK. Dengan demikian dapat disimpulkan bahwa tingkat kemiskinan di desa Peunaga Pasi semakin menurun dengan adanya Badan Usaha Milik Desa.

Kegiatan Badan Usaha Milik Desa di Peunga Pasi dikelola oleh pengurrus dan beberapa perangkat desa lainnya. Selain itu seluruh masyarakat juga terlibat dan ikut berpartisipasi dalam kegiatan BUMDes ini, dengan kata lain masyarakat bekerja di BUMDes secara bergiliran sehingga semua masyarakat merasakan keberadaan dari BUMDes atau Badan Usaha Milik Desa.

Badan Usaha Mllik Desa selain berdampak terhadap kemiskinan juga membawa pengaruh positif terhadap kesejahteraan masyarakat. Menurut pengamatan peneliti desa Peunaga Pasi tergolong dalam desa maju dan msayarakatnya juga rata rata tergolong mampu dengan pendapatan dan kondisi rumah serta asset yang memadai. Dengan demikian dapat disimpulkan bahwa secara umum masyarakat peunaga pasi hidupnya sejahtera dan tercukupi.

\section{Kesimpulan}

1. Rekomendasi ke depan untuk pemerintah pusat lebih di tingkatkan lagi Dana untuk BUMDes supaya kegiatan BUMDes lebih maksimal dan lebih berkembang untuk kemajuan desa.

2. Pemerintah desa juga perlu perhatian 
khususnya memaksimalkan pembangunan BUMDes seperti memberikan pelatihan,pembinaan dan pengembangan kepada para pengurus terkait dengan Pengelolaan dana, agar manfaatnya bisa sama-sama dirasakan oleh masyarakat desa.

3. BUMDes Desa peunaga pasi diharapkan bisa meningkatkan pemberdayaan masyarakat kedepannya.Misalnya dengan memperbanyak Produk Unggulan Desa ( PRUDES) yang dijalankan oleh msyarakat dan dipasarkan oleh BUMDES.

4. Peran Badan Usaha Milik Desa perlu diteliti secara lebih detail dengan beberapa amatan lain yang semakin bear dan waktu observasi yang lebih panjang serta pentingnya meningkatkan pendekatan dengan cara bersosialisasi dengan masyarakat agar data yang ditemukan dapat lebih mendalam.

5. Dalam penelitian selanjutnya diharapkan tidak hanya berfokus pada sekedar menemukan dampak Badan Usaha Milik Desa namun bisa sampai menciptakan halhal maupun temuan-temuan yang baru untuk peningkatan Badan Usaha Milik Desa misalnya produk unggulan Desa (PRUDES). Selain itu, peneliti menaruh harapan pada penelitian ini agar menjadi bahan cambukan ataupun kritikan kepada Pemerintah Daerah, Pemerintah Desa, Pengurus Operasional BUMDes dan Masyarakat agar menjalankan dan memanfaatkan dengan baik Badan Usaha Milik Desa demi terciptanya kesejahteraan ekonomi masyarakat dan desa.Selanjutnya juga harus mengadakan program pelatihan untuk para pengurus Badan Usaha Milik Desa supaya semakin menguasai teknologi dengan lebih baik lagi.

\section{DAFTAR PUSTAKA}

Ade Eka Kurniawan. 2016. Peranan Badan Usaha Milik Desa (Bumdes) Dalam Peningkatan Pendapatan Asli Desa.

Gufran,Hajairin.2019. Pelaksanaan BUMdes dalam meningkatkan pendapatan masyarakat dan pendapatan asli desa di kecamatan Belo Kabupaten Bima. Jurnal IImiah IImu Sosial dan Humaniora.

Amelia Sri Kusuma Dewi.2014. Peranan Badan Usaha Milik Desa (Bumdes) Sebagai Upaya Dalam Meningkatkan Pendapatan Asli Desa (PADes) Serta Menumbuhkan Perekonomian Desa. Journal of Rural and Development.
Sinta Hariyati.2015. Persepsi Masyarakat Terhadap Pembangunan Jembatan Mahkota li Di Kota Samarinda. 3 (2) : 585-596 ISSN 0000-0000. eJournal IImu Pemerintahan.

Nur Fitriyati.2016. Studi Tentang Pengelolaan Pasar Tradisional Pada Unit Pasar Suruh Kabupaten Semarang.

Nunung Nurwati. 2008. "Kemiskinan : Model Pengukuran, Permasalahan dan Alternatif Kebijakan". Jurnal Kependudukan Padjadjaran, Vol. 10, No. 1, Januari $2008: 1-11$. 